\title{
Speed Control of Induction Motor using LQG
}

\author{
Hari Maghfiroh ${ }^{1 *}$, Irwan Iftadi ${ }^{2}$, Augustinus Sujono ${ }^{3}$ \\ ${ }^{1,2,3}$ Department of Electrical Engineering, Universitas Sebelas Maret, Surakarta, Indonesia \\ Email: ${ }^{1}$ hari.maghfiroh@ staff.uns.ac.id, ${ }^{2}$ iftadi@ gmail.com, ${ }^{3}$ agus.sjn.te16@ gmail.com
}

*Corresponding Author

\begin{abstract}
The electric motor is one of the technological developments which can support the production process. Not only in the manufacturing, but also in the transportation sector. The AC motor is divided into the synchronous and asynchronous motor. One type of asynchronous motor which widely used is the induction motor. In this study, the application of the IFOC control method and the LQG speed control method will be used to control the speed of an induction motor. The PID algorithm is also used as a comparison. Tests were carried out using MATLAB software. The speed variation and load variation are tested to validate the controller performance. PID is superior in terms of settling time and IAE. On the other hand, LQG is better in energy consumption. In terms of IAE, LQG has a higher value compared to PID by up to $56.67 \%$. On the other hand, LQG is superior in terms of energy, which is $8.38 \%$ more efficient.
\end{abstract}

\section{Keywords-induction motor, speed, IFOC, LQG}

\section{INTRODUCTION}

The electric motor is one of the technological developments which can support the production process. Not only in the manufacturing, but also in the transportation sector. Base on the supply current, there are two kinds of an electric motor which are AC and DC motor. Although the DC motor is simpler in control, it uses a mechanical commutator (brush) which causes high maintenance cost [1]. Therefore, an $\mathrm{AC}$ motor is chosen.

The AC motor is divided into the synchronous and asynchronous motor. One type of asynchronous motor which widely used is the induction motor. The induction motor is cost-effective in installation as well as in maintenance [2] [3]. The induction motors are mainly used and consume approximately $60 \%$ of the total energy of the plant [4].

There are many methods of controlling the speed of an induction motor, known as Variable Frequency Drive (VFD). As can be seen in Fig.1, VFD can be done with a sensor (sensored) or without a sensor (sensorless). The sensor referred to here is a speed sensor. In this study, the sensorbased control method will be used because the algorithm is easier.

Sensored control itself is divided into scalar control and vector control. Scalar control is simple, easy, and parameters independent modeling [5-9]. On the other hand, the vector control has high controlling performance and thus it is most widely used [10-13]. There are two categories of vector control methods, namely Field Oriented Control (FOC) and Direct Torque Control (DTC). Both have their own advantages and disadvantages. More specifically, the FOC method is divided into Indirect Field Oriented Control
(IFOC). The IFOC method has been widely used as in [1415].

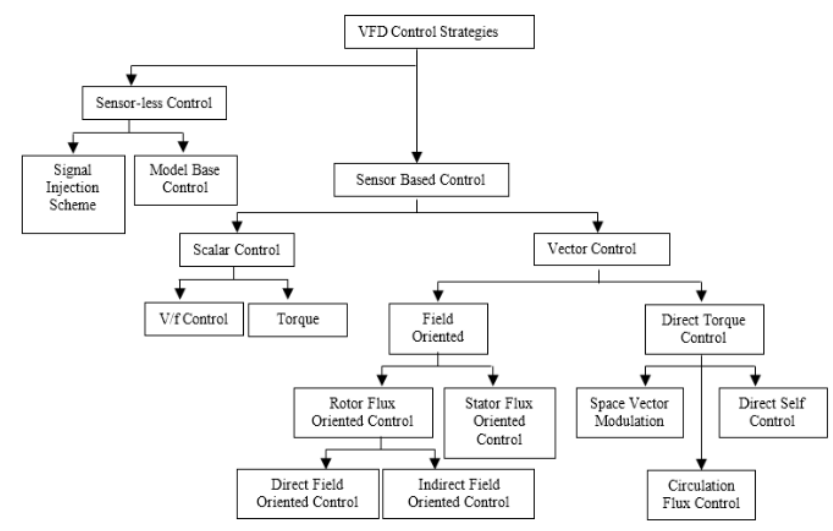

Fig.1. Induction motor control classification [16]

The FOC and DTC methods are basically torque control, so to perform speed control an additional speed control method is required. There are also many speed control algorithms for induction motor speed control, such as PID [17], the fuzzy logic controller (FLC) [18-19], sliding mode controller (SMC) [10], Artificial Neural Network (ANN) [20$21]$, and the combination between conventional and artificial intelligent method as can be found in [22-24].

In this study, the application of the IFOC control method and the LQG speed control method will be used to control the speed of an induction motor. The performance and energy consumption will be analyzed. Tests were carried out using MATLAB software. The PID algorithm is also used as a comparison.

\section{MATERIAL AND METHOD}

\section{A. Induction Motor Control}

In general, the block diagram of VFD components can be seen in Fig. 2. The encoder is used as a speed sensor because the control method used is the sensored base. In Fig. 2, Torque Control is embedded in the inverter, so the controller functions are as speed control. Speed data is required for both torque control and speed control so that it is fed back to the inverter and controller. The output of the controller is a torque reference as a reference for the torque control of the inverter. 


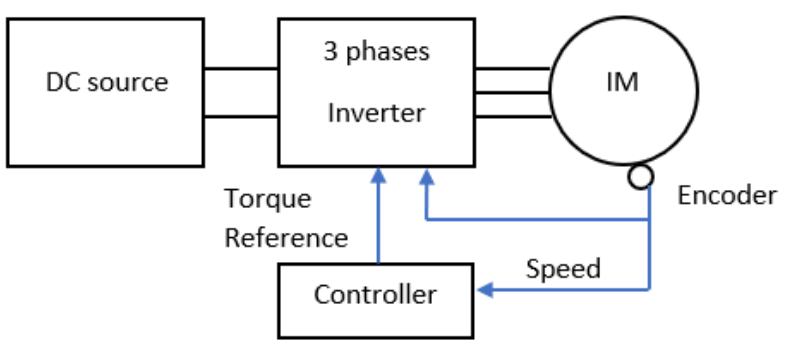

Fig. 2. General component of IM VFD

Fig. 3 (a) shows the simulation circuit for induction motor speed control in MATLAB Simulink. The torque control method used is Vector Control, while the speed control algorithms that will be used are PID and LQG. Fig. 3 (b) shows the block for speed control algorithm selection, the blue color is the PID block while the LQG block is white. Fig. 3 (c) shows the circuit in the LQG block which consists of the LQR control and observer which is the Kalman Filter.

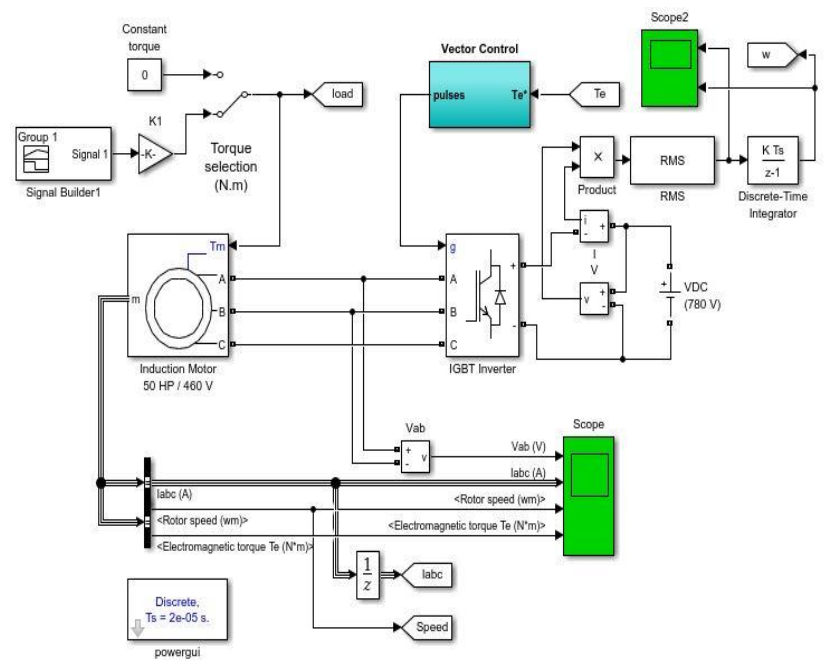

(a) IM torque control

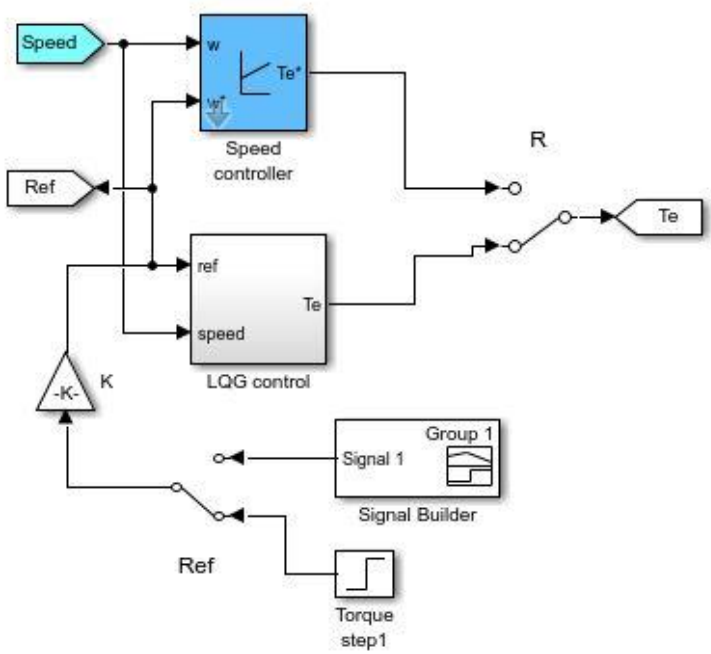

(b) Control selection

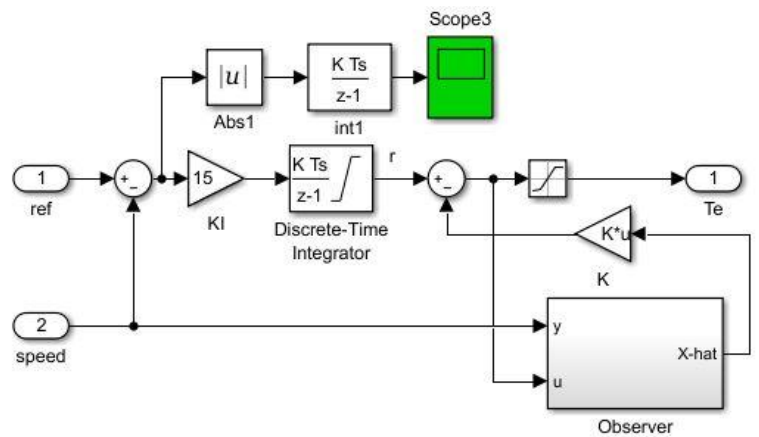

(c) LQG structure

Fig. 3. VFD of IM in MATLAB Simulation

\section{B. LQG Design}

LQG (Linear Quadratic Gaussian) control is one kind of optimal control. It is the combination between LQR (Linear Quadratic Regulator) and Kalman Filter [25]. LQG solves the weakness of LQR control which requires the number of sensors as the number of states and replaces them with an observer, Kalman Filter [1]. This is very useful since not all the states of the system can be measured. Replacing the sensors with an observer also reducing the cost of the system. However, it does not guarantee the robustness of the system against uncertainties in operating conditions [26].

The block diagram of LQG control is shown in Fig.4. Kalman filter used to estimate the state of the system based on system output. The estimated state is sent to LQR control as state feedback. Kalman Filter needs a system model to estimate the state of the system; therefore, a system model is needed. The system model is constructed base on mathematical equations or modeling base on input-output data of the system. The second method is also known as black-box modeling [27].

Some researchers use the first method to get the system model such as [28-30]. On the other hand, [31] and [32], use the second method by taking data from the input-output of the system to find the system model. In the first method, system parameters are required; therefore, it not suitable for hardware implementation where no parameters of the system are ready. In this research, the second method of modeling is chosen. The flow diagram of the LQG control design process is depicted in Fig. 5.

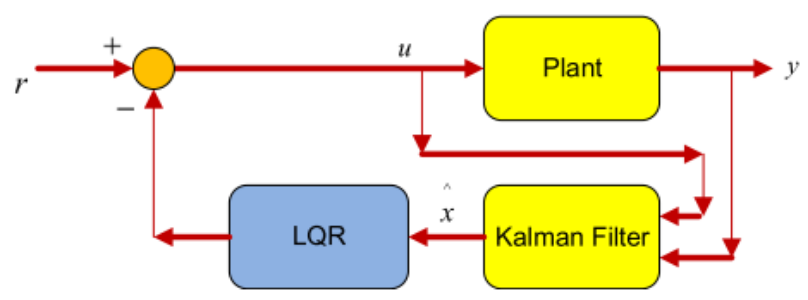

Fig. 4. LQG: combination of LQR and Kalman Filter [30]

\section{RESULTS AND DISCUSSION}

The tests are performed on the speed variation and load variation. As a comparison, testing was also carried out using the PID method. The tolerance of the speed control is $\pm 2 \%$. 


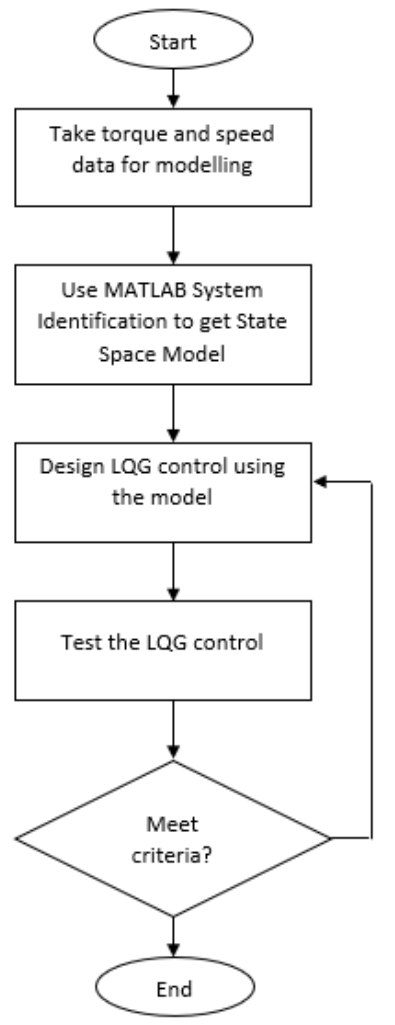

Fig. 5. LQG control design process

\section{A. Speed Variation Test}

A speed variation test is performed to know the performance of the control method used in tracking the given speed set-points. In addition, to find out how fast the system is stable when starting from the initial condition and speed changes. Fig. 6 shows the simulation results of the speed variation testing. There are 3 graphs: a velocity graph, an Integral of Absolute Error (IAE) graph, and an energy graph. IAE is used as a control system performance parameter. Meanwhile, energy, obtained from the measurement of DC inverter input, is used as an indicator of energy consumption resulting from the control method used.

Fig. 6 (a) shows that the speed response of the two control methods can track the speed set-point well. Based on the graph, PID has a faster rise time in speed changes than the LQG method. However, it seems that the two of them reach the set-point almost simultaneously. While the quantitative results can be seen in Table 1-3.

Table 1 shows the results at the first set-point, $50 \mathrm{rad} / \mathrm{s}$. PID excels in settling time and IAE. On the other hand, LQG has less overshoot (OS) and energy than PID. The response of the $80 \mathrm{rad} / \mathrm{s}$ set-point is summarized in Table 2. At this second set-point, the results are the same as the first response, namely, PID is superior in terms of settling time and IAE while LQR is superior in terms of overshoot and energy. In the reduced speed, Table 3, LQR is only superior on the energy side compared to PID. The calculation of the parameter value of the settling time for the $80 \mathrm{rad} / \mathrm{s}$ and 60 $\mathrm{rad} / \mathrm{s}$ set-points is from 3 seconds and 6 seconds, respectively. Meanwhile, the IAE and Energy values are accumulative from the beginning, 0 seconds.
TABLE I. Result AT SET-PoINT 50

\begin{tabular}{lllll}
\hline $\begin{array}{l}\text { Control } \\
\text { Algorithm }\end{array}$ & $\begin{array}{l}\text { Settling } \\
\text { Time (s) }\end{array}$ & \% OS & IAE & Energy (J) \\
\hline PID & 1.3 & 59.56 & 13.82 & 58,275 \\
LQG & 1.5 & 54.09 & 22.14 & 48,416 \\
\hline
\end{tabular}

TABLE II. RESUlt AT SET-Point 80

\begin{tabular}{lllll}
\hline $\begin{array}{l}\text { Control } \\
\text { Algorithm }\end{array}$ & $\begin{array}{l}\text { Settling } \\
\text { Time (s) }\end{array}$ & \% OS & IAE & Energy (J) \\
\hline PID & 3.95 & 84.07 & 19.70 & 103,320 \\
LQG & 4.34 & 82.64 & 35.52 & 90,176 \\
\hline
\end{tabular}

TABLE III. RESUlt AT SET-Point 60

\begin{tabular}{lllll}
\hline $\begin{array}{l}\text { Control } \\
\text { Algorithm }\end{array}$ & $\begin{array}{l}\text { Settling } \\
\text { Time (s) }\end{array}$ & \% US & IAE & Energy (J) \\
\hline PID & 7.04 & 57.46 & 23.34 & 135,400 \\
LQG & 7.44 & 58.24 & 44.35 & 114,880 \\
\hline
\end{tabular}

\section{B. Load Variation Test}

The second test is load variation. This test aims to determine the performance of the motor speed control system when loaded and load changes. In electric vehicle applications, this test can reflect conditions where road conditions are up and down.

The results of the load variation test can be seen in Fig.7. It can be seen in the addition and reduction of load that the speed changes. From the speed graph, Fig. 7 (a), the overshoot (OS) and undershoot (US) of the LQG method on load changes are greater. Meanwhile, from the IAE perspective, Fig. 7. (b), the IAE of PID is smaller than LQG as in the speed variation test results. LQG is still superior in terms of energy. The complete results are summarized in Table 4. Table 4 shows that PID is superior in all criteria except energy. Undershoot data is retrieved when the load is added, while overshoot data is retrieved when the load is reduced.

TABLE IV. RESULT OF LOAD VARIATION

\begin{tabular}{llllll}
\hline $\begin{array}{l}\text { Control } \\
\text { Algorithm }\end{array}$ & $\begin{array}{l}\text { Settling } \\
\text { Time (s) }\end{array}$ & \%US & \% OS & IAE & $\begin{array}{l}\text { Energy } \\
(\mathbf{J})\end{array}$ \\
\hline PID & 1.59 & 68.40 & 70.53 & 26.98 & 171,700 \\
LQG & 1.61 & 68.87 & 70.80 & 34.99 & 166,470 \\
\hline
\end{tabular}

The test results are quite varied, but in general, PID is superior in terms of settling time and IAE, while LQR is superior in terms of energy. To be able to conclude quantitatively, the results of the first and second tests are averaged on the IAE and Energy sides as shown in Table 5. Then the IAE and Energy percentages are calculated with the PID value as the basis so that the PID value is made $100 \%$. From this, in terms of IAE, LQG has a higher value compared to PID by up to $56.67 \%$. On the other hand, LQG is superior in terms of energy, which is $8.38 \%$ more efficient. 


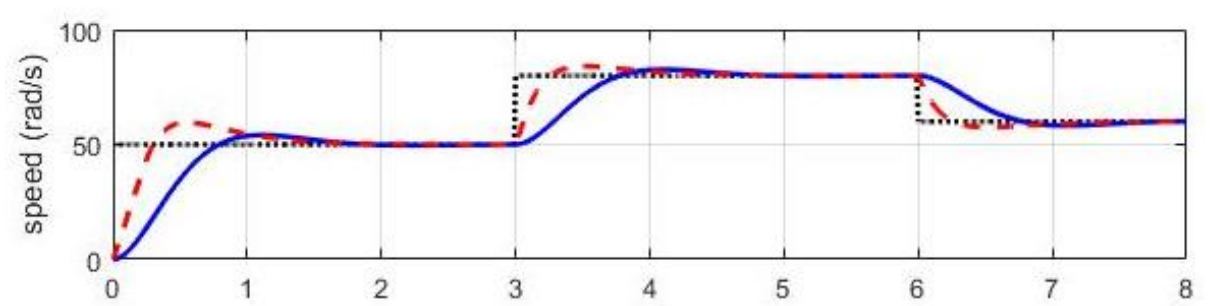

(a)

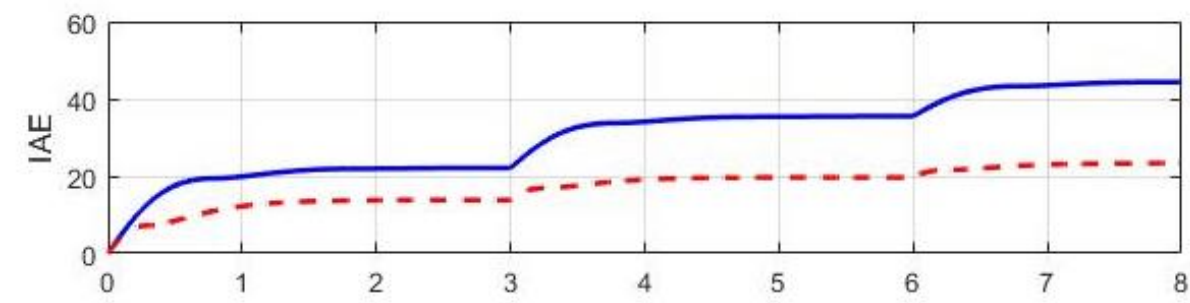

(b)

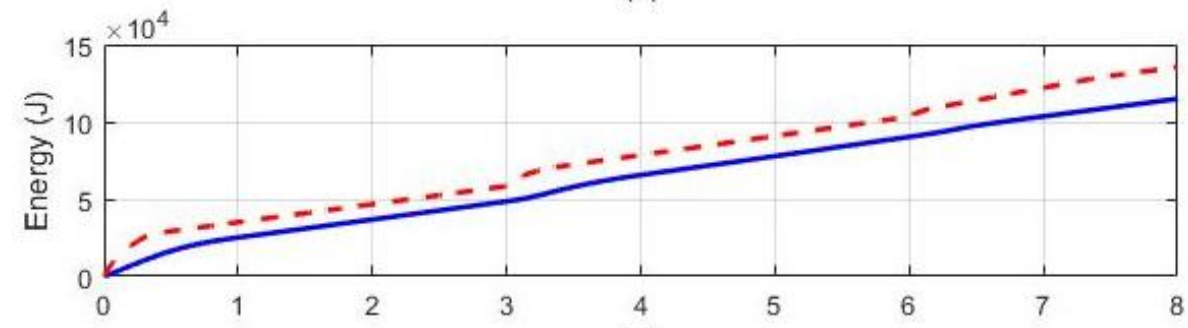

(c)

time (s) $\quad$....... Ref - LQG - - PID

Fig. 6. Speed variation test result

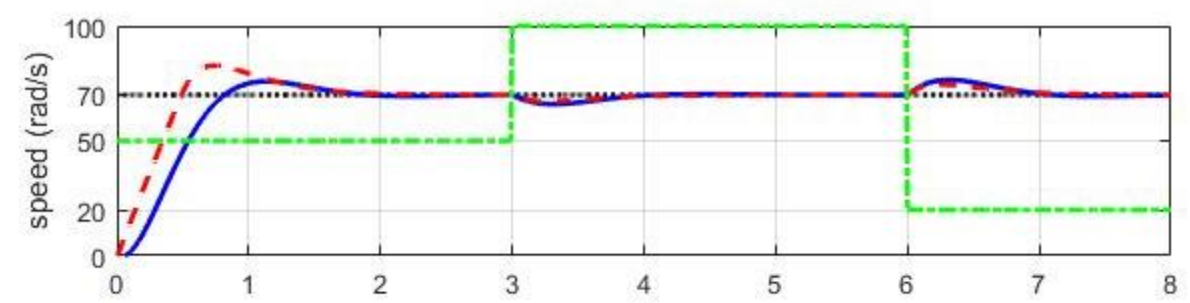

(a)

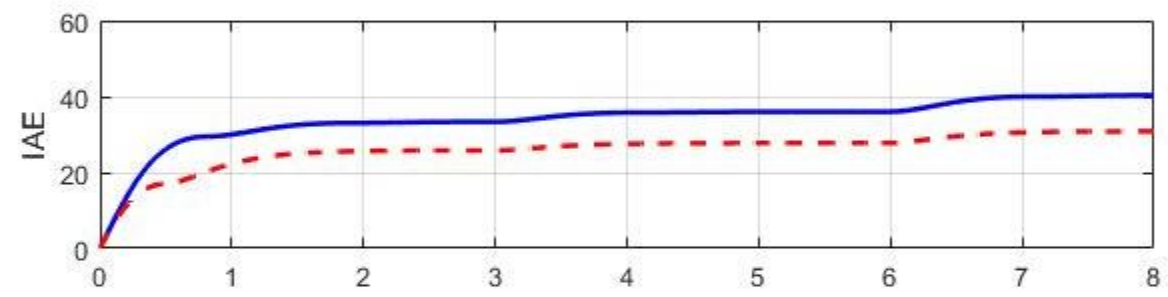

(b)

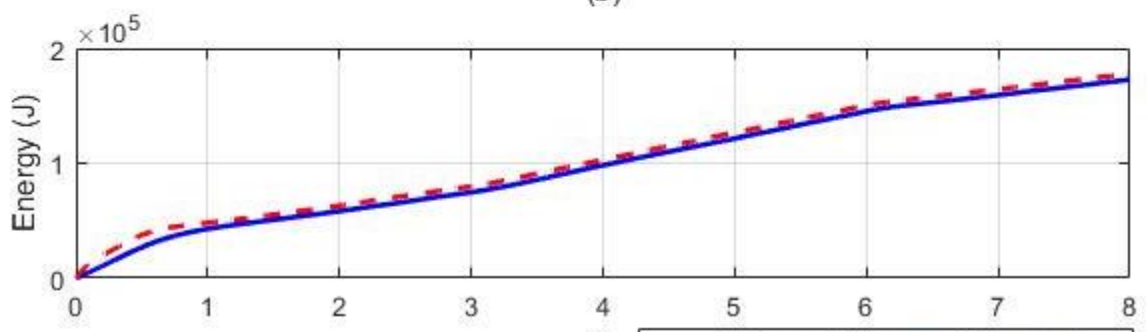

(c) ….... Ref - LQG - - PID -..-- Load time (s)

Fig. 7. Load variation test result 
TABLE V. PID AND LQR COMPARISON RESULT

\begin{tabular}{lllll}
\hline $\begin{array}{l}\text { Control } \\
\text { Algorithm }\end{array}$ & IAE & \% IAE & $\begin{array}{l}\text { Energy } \\
(\mathbf{J})\end{array}$ & $\begin{array}{l}\text { \% } \\
\text { Energy }\end{array}$ \\
\hline PID & 25.16 & 100 & 153,550 & 100 \\
LQG & 39.67 & 156.67 & 140,675 & 91.62 \\
\hline
\end{tabular}

In the process of designing the control system, PID is very easy and simple. However, it cannot be optimized to save energy consumption because it does not have an objective function like LQG. LQG is included in the optimal control which has an objective function and can minimize control energy. However, the algorithm is more complex. Therefore, the choice is based on the requirement, whether looking for a simple and easy one or having an objective function as well. The addition of objective functions to PID can be done by combining it with other methods such as Artificial Intelligent (AI).

\section{CONSLUSION}

The design and simulation of speed control of induction motor using the LQG method have been done. Both performance and energy are analyzed and compared with conventional PID control. LQG control is more complicated compare with PID. The speed variation and load variation are tested to validate the controller performance. PID is superior in terms of settling time and IAE. On the other hand, LQG is better in energy consumption. In terms of IAE, LQG has a higher value compared to PID by up to $56.67 \%$. On the other hand, LQG is superior in terms of energy, which can save energy by up to $8.38 \%$ compared to PID.

\section{ACKNOWLEDGMENT}

The authors would like to thank Instrumentation and Control Laboratory, Faculty of Engineering, Sebelas Maret University which supports and facilitate this research, and to the reviewer and editor who give suggestions and advice to improve the paper quality.

\section{REFERENCES}

[1] H. Maghfiroh, C. Hermanu, M. H. Ibrahim, M. Anwar, and A. Ramelan, "Hybrid fuzzy-PID like optimal control to reduce energy consumption," TELKOMNIKA, vol. 18, no. 4, pp. 2053-2061, 2020.

[2] M. Swargiary, J. Dey, and T. K. Saha, "Optimal Speed Control of Induction Motor Based on Linear Quadratic Regulator Theory," in 2015 Annual IEEE India Conference (INDICON), 2015.

[3] O. S. Ebrahim and P. K. Jain, "LQR-based stator field oriented control for the induction motor drives," Conf. Proc. - IEEE Appl. Power Electron. Conf. Expo. - APEC, no. 5, pp. 1126-1131, 2008.

[4] M. Magzoub, N. Saad, R. Ibrahim and M. Irfan, An experimental demonstration of hybrid fuzzy-fuzzyspace- vector control on AC variable speed drives, Neural Computing \& Applications, pp. 1-16, 2017.

[5] Suetake M, da Silva IN, Goedtel A. Embedded DSP-based compact fuzzy system and its application for induction-motor speed control. IEEE Transactions on Industrial Electronics, vol. 58, pp. 750-60, 2011.

[6] CMFS Reza, Islam MD, Mekhilef S. A review of reliable and energy efficient direct torque-controlled induction motor drives. Renewable Sustainable Energy Review, vol. 37, pp. 919-32, 2014.

[7] Dos Santos TH, Goedtel A, da Silva SAO, Suetake M. Scalar control of an induction motor using a neural sensorless technique. Electrical Power Systm Research, vol. 108, pp. 322-30, 2014.
[8] Allirani S, Jagannathan V. Direct torque control technique in induction motor drives - a review. Journal of Theory \& Applications of Information Technology, vol. 60, 2014.

[9] Sarhan H. Efficiency optimization of vector-controlled induction motor drive. International Journal of Advance Engineering Technology, vol. 7, 2014.

[10] Demirtas M. DSP-based sliding mode speed control of induction motor using neuro-genetic structure. Expert System Applications, vol. 36, pp. 33-40, 2009.

[11] Rong-Jong W, Jeng-Dao L, Kuo-Min L. Robust decoupled control of direct fieldoriented induction motor drive. 5th Asian Control Conference, pp. 1346-1353, 2004.

[12] Hedjar R, Boucher P, Dumur D. Robust nonlinear recedinghorizon control of induction motors. International Journal of Electrical Power Energy System, vol. 46, pp. 353-65, 2013.

[13] Sutikno T, Idris NRN, Jidin A. A review of direct torque control of induction motors for sustainable reliability and energy efficient drives. Renewable Sustainable Energy Review, vol. 32, pp. 54858,2014

[14] I. K. Bousserhanel, A. Hazzabl, M. Rahlw, M. Kamli, and B. Mazari, "Adaptive PI Controller using Fuzzy System Optimized by Genetic Algorithm for Induction Motor Control," in IEEE International Power Electronics Congress, 2006.

[15] A. Hazzab, I. K. Bousserhane, and M. Kamli, "Design of a Fuzzy Sliding Mode Controller by Genetic Algorithms for Induction Machine Speed Control," Int. J. Emerg. Electr. Power Syst., vol. 1, no. 2, 2004.

[16] A. Alwadie, "A Concise Review of Control Techniques for Reliable and Efficient Control of Induction Motor," Int J. Power Electron. Drive Syst., vol. 9, no. 3, pp. 1124-1139, 2018.

[17] M.A. Hannan, Jamal A. Ali, Azah Mohamed, Aini Hussain, Optimization techniques to enhance the performance of induction motor drives: a review, Renewable and Sustainable Energy Reviews, 2017.

[18] A. J. Fattah and I. A. Qader, "Performance and Comparison Analysis of Speed Control of Induction Motors using Improved Hybrid PID-Fuzzy Controller," in 2015 IEEE Int. Conference on Electro/Information Technology (EIT), 2015, pp. 575-580.

[19] B. Umesh and S. Sanjay, "Speed Control of Three Phase Induction Motor Using Fuzzy-PID Controller," Int. J. Eng. Res. Technol., vol. 2, no. 11, pp. 3794-3799, 2013.

[20] Lin FJ, Huang PK, Chou WD. A genetic algorithm based recurrent fuzzy neural network for linear induction motor servo drive. J Chin Inst Eng 2007; 30:801-17.

[21] Lin C-K. Radial basis function neural network-based adaptive critic control of induction motors. Appl Softw Comput 2011; 11:3066-74.

[22] Bousserhane IK, Hazzab A, Rahli M, Kamli M, Mazari B. Adaptive PI Controller using Fuzzy System Optimized by Genetic Algorithm for Induction Motor Control. 10th IEEE International Power Electronics Congress, pp. 1-8, 2006.

[23] Ali JA, Hannan M, Mohamed A. Improved indirect field-oriented control of induction motor drive based PSO algorithm. Jurnal Teknologi, vol. 78, 2016.

[24] Ali JA, Hannan M, Mohamed A. Gravitational search algorithmbased tuning of a PI speed controller for an induction motor drive. IOP Conference Series: Earth and Environmental Science: IOP Publishing. pp. 12001- 12004, 2016.

[25] W. M. W. Syahidah, O. Rosli, M. A. Joraimee, and A. Norhidayah, "Linear Quadratic Gaussian ( LQG ) Controller Design for Servo Motor," AENSI J., vol. 8, no. 4, pp. 700-713, 2014.

[26] N. K. Roy, H. R. Pota, M. A. Mahmud, and M. J. Hossain, "Voltage control of emerging distribution systems with induction motor loads using robust LQG approach," Int Trans. Electr. Energy Syst., no. April 2013, pp. 927-943, 2014.

[27] N. H. M. Nasir, K. K. Ib, and M. K. I. Ahmad, "Comparative Study on Mathematical and Black Box Modelling Approaches of Musculoskeletal System," in International Seminar on the Application of Science \& Mathematics, 2011, pp. 1-8.

[28] Ilham, "KENDALI KECEPATAN MOTOR INDUKSI 3 PHASA MENGGUNAKAN LQR ( LINEAR QUADRATIC REGULATOR )," Inspir. J. Teknol. Inf. dan Komun., vol. 3, no. 1, pp. 61-68, 2013.

[29] O. S. Ebrahim, M. F. Salem, P. K. Jain, and M. A. Badr, "Application of linear quadratic regulator theory to the stator field- 
oriented control of induction motors," IET Electr. Power Appl., vol. 4, no. 8, p. 637, 2010.

[30] T. Abut, "Modeling and Optimal Control of a DC Motor," Int. J. od Eng. Trends Technol., vol. 32, no. 3, pp. 146-150, 2016.

[31] A. Ramelan, J. S. Saputro, C. Hermanu, M. H. Ibrahim, and S. Pramono, "Desain and Simulation Linear Quadratic Gaussian
(LQG) for Pan-Tilt Face Tracking Camera Servos," in AIP Conference Proceedings, 2020.

[32] I. Ajiprasetyo and D. Wibawa, "Design and Implementation Control LQG for DC Motor Velocity," e-Proceeding Eng., vol. 2, no. 2,2015 